\title{
Motor Imagery and Merleau-Pontyian Accounts of Skilled Action
}

\author{
J.C. BERENDZEN
}

Loyola University New Orleans

\begin{abstract}
Maurice Merleau-Ponty is often interpreted as claiming that opportunities for action are directly present in perceptual experience. However, he does not provide much evidence for how or why this would occur, and one can doubt that this is an appropriate interpretation of his phenomenological descriptions. In particular, it could be argued the Merleau-Pontyian descriptions mistakenly attribute pre-perceptual or postperceptual elements such as allocation of attention or judgment to the perceptual experience itself. This paper argues for the Merleau-Pontyian idea that opportunities for action are present in perceptual experience. It further argues that the phenomenological descriptions can be supported and explained via reference to contemporary research on motor imagery. In particular, it will be argued that non-conscious, covert motor imagery is used to prepare for and regulate skilled actions, and that it is plausible that this imagery combines with perception (likely vision) to create a single experience of the environment as enabling action. The paper will also show that contemporary views on motor imagery are broadly compatible with Merleau-Ponty's aims.
\end{abstract}

$\mathrm{I}^{\mathrm{n}}$ $\mathrm{n}$ various passages in his early works, Maurice Merleau-Ponty suggests that when immersed in skilled action, agents literally perceive the environmental scene as presenting opportunities for action. One famous example from The Structure of Behavior involves a soccer player:

For the player in action the soccer field . . . is pervaded with lines of force (the "side lines"; those which demarcate the "penalty area") and articulated in sectors (for example, the "openings" between the adversaries) which call for a certain mode of action and which initiate and guide the action as if the player were unaware of it ... Each maneuver undertaken by the player modifies the character of the field and establishes in it new lines of force in which the action in turn unfolds and is accomplished, again altering the phenomenal field. (I983: I68-169, translation amended)

Contact: J.C. Berendzen <jberendz@loyno.edu> 
Insofar as they are taken to be alterations of the "phenomenal field," one might understand the putative modifications in the character of the field as being modifications of the phenomenal character of the field as experienced. Thus the soccer player would directly experience the "sectors" in perception. ${ }^{\mathrm{I}}$

Another characteristic example, this time found in Merleau-Ponty's Phenomenology of Perception, involves an organist:

It is said that an experienced organist is capable of playing an organ with which he is unfamiliar ... He does not learn positions in objective space for each stop and each pedal, nor does he entrust such positions to "memory." During the rehearsal-just as during the performance-the stops, the pedals, and the keyboards are presented to him as powers of such and such an emotional or musical value, and their position as those places through which this value appears in the world. (201 2: I46-I47)

Insofar as the organist has the parts of the organ "presented to him" as capable of producing musical and emotional values, the suggestion is that they show up in this way in perceptual experience.

To be fair, these passages should allow for multiple interpretations; it is not obvious, for instance, that in the soccer example modifications to the "phenomenal field" imply modifications to what contemporary philosophers of perception call "phenomenal character." But it is common in the secondary scholarship for Merleau-Ponty to be interpreted in the manner suggested above. For example, Hubert Dreyfus finds in Merleau-Ponty the view that a person with expert-level skills "not only sees what needs to be achieved" but also "sees how to achieve his goal" (2002a: 37I-372). The "sees" here is clearly meant to refer to perceptual experience; as he puts it, "what one has learned appears in the way the world shows up" (2002a: 373). Shortly after considering Merleau-Ponty's soccer example, Komarine Romdenh-Romluc puts the point more directly with another example: "the martial artist ... perceives her situation as requiring a certain sort of behaviour . . . her opponent's fist is seen as an opportunity to duck, an unguarded chest presented as an opportunity to deliver a kick, etc.” (2007: 46). ${ }^{2}$ Here the claim clearly is that the martial artist directly sees the opportunities for action.

I. While Merleau-Ponty says that the player is "unaware," it should be clear that the player lacks awareness of the initiation and guidance, which is to say that the player is not aware of consciously choosing a course of action. Merleau-Ponty does not mean to say that the player is visually unaware, and this is suggested by the reference to the "phenomenal field."

2. In a response to Romdenh-Romluc's paper which is generally critical of her overall argument, Dreyfus does approve of this aspect of her interpretation of Merleau-Ponty, and he notes regarding the soccer player example that "when the player is totally absorbed in his task ... he sees the world as full of opportunities and threats that 'pull forth' appropriate responses from him." See Dreyfus (2007: 60). 
One can certainly question whether it is plausible that such opportunities directly show up in perceptual experience in the sense that they become contents of conscious visual experience (or experience in or across other modalities). Those who do not share the putative Merleau-Pontyian view could argue that the relevant elements of the experience should be thought of as pre-perceptual or postperceptual. ${ }^{3}$ It is easy to think of a basis for the latter type of counter argument; for instance, the skilled actors might have the same perceptual experience as those who lack the relevant skill, but be better able to make decisions using that perceptual information. Instances of the former type might be a bit more difficult to see, but consider the possibility that the skilled actors know better where to focus or have better attention. There is an obvious sense in which this would lead them to have qualitatively different visual experiences from other players; if a great soccer player like Cristiano Ronaldo focuses on or attends to something that I do not, he will see things that I do not. But the important point here is that the difference lies in the focusing and not in the visual contents themselves. If I could attend to and see the same things as Ronaldo, we would have the exact same visual contents. Thus, for the person who rejects the Merleau-Pontyian view the relevant differences could boil down to pre-perceptual differences that determine the allocation of attention.

Those who want to vindicate the Merleau-Pontyian contention that action opportunities are directly presented in perceptual experience often turn to ecological perceptual psychology, and in particular to J.J. Gibson's concept of affordance, for support. ${ }^{4}$ In this paper I will take a different direction, however, and argue that recent research into motor imagery provides strong support for the MerleauPontyian phenomenological descriptions. ${ }^{5}$ Specifically, I will argue that motor imagery enables the skilled actor to augment the perceptual scene in such a way that

3. The two species of argument that I am considering here (that the effect is pre-perceptual or post-perceptual) are quite common. In particular, they are often made against cognitive penetration claims; see Deroy (20I2).

4. For example, Dreyfus (2002a) mentions affordances, but he has some reasons for thinking that Gibson's view does not perfectly fit Merleau-Ponty's; see Dreyfus and Kelly (2007: note 3). Romdenh-Romluc (2007) does not mention affordances, but she mentions them in other similar discussions; see Romdenh-Romluc (20II). For other discussions of Merleau-Ponty and affordances see Glotzback and Heft (I982) and Sanders (I993).

5. It has been argued that motor simulation--which plays an important role in my consideration of motor imagery below--can play the role of affordances. See, for example Garbarini and Adenzato (2004), who base their conception of simulation on research on canonical neurons. Also, Gallese (2000) connects motor simulation to Gibson's views (without specifically mentioning affordances). Both note that their views require some departure from Gibson's work, though, and their reasons are somewhat similar to those offered in Dreyfus and Kelly (2007: note 3). Gallese also ties his view to Merleau-Ponty, though only in cursory fashion. For some arguments against tying affordance to motor simulation, see Declerck (20I3). I am not taking a hard stance on whether or not the view I am espousing in this paper fits with Gibson's work, though I suspect that it does not fit entirely well (see footnote 22). 
opportunities for action show up directly, rather than being due to pre-perceptual focusing or post-perceptual decision making.

This consideration of motor imagery and the perception of action opportunities will have two general aims. The first is to show that motor imagery research can support the type of phenomenological descriptions offered above and provide an empirically plausible explanation of how such phenomena occur. Such an explanation is not typically provided by Merleau-Ponty or his interpreters, so this paper should add to the literature in that regard. The second aim is to show that the motor imagery view that is marshaled to support and explain the phenomenological descriptions is compatible with a broadly Merleau-Pontyian view on perception and action. A bit of explanation is in order. The aim is not to argue that the motor imagery view is in fact Merleau-Ponty's view (it is not). Nor is the aim to anachronistically argue that the motor imagery view is one that Merleau-Ponty would accept if given the chance. Rather, the aim is to show that the motor imagery view fits in with the kinds of general commitments regarding perception and action that Merleau-Ponty establishes in his early works (primarily The Structure of Behavior and Phenomenology of Perception).

The paper will proceed according to the following plan. Section I will provide a general overview of the recent research on motor imagery. Section 2 will discuss the extent to which the motor imagery research fits with Merleau-Ponty's views. Section 3 will then discuss the idea that motor imagery can qualitatively affect perceptual experience. This will be key to establishing the idea that opportunities for action are directly present in perception. Section 4 will then provide some concluding remarks on the way in which motor imagery can be used to vindicate the Merleau-Pontyian phenomenological descriptions. This will involve showing that motor imagery's effect on perception is not (solely, at least) pre-perceptual or post-perceptual.

\section{Skillful Action and Motor Imagery}

Subjects can be said to engage in motor imagery when they imagine that they are engaging in a particular action. The term "motor image" does not, however, refer to mental imagery that depicts the subject engaging in the action from a thirdperson perspective. Nor is motor imagery merely visual mental imagery of actions (though visual images are often connected to motor images). As Marc Jeannerod puts the point, motor images can be "experienced from within, as the result of the 'first person' process involving mostly a kinesthetic representation of the action" (I995: I4I9). Jeannerod takes motor images to be a "prototypical form of action 
representation" insofar as they represent a goal that will be fulfilled if the imagined action is completed. ${ }^{6}$

It is important to emphasize that motor imagery is genuinely imagery in the same sense that visual imagery (or imagery in other modalities) is imagery. The common view in the contemporary philosophical and scientific literature is that mental imagery is, in the words of Thomas (20I4), "quasi-perceptual experience; it resembles perceptual experience, but occurs in the absence of the appropriate external stimuli." Typically this point is put in representationalist terms; see, for example, Kosslyn, Thompson, and Ganis's claim that imagery occurs "when a representation of the type created during the initial phases of perception is present but the stimulus is not actually being perceived" (2006: 4). One need not describe the link between imagery and perception in representationalist terms, however. For example, in presenting his enactivist theory Evan Thompson describes mental imagery as "a subjectively simulated or emulated perceptual experience" (2007: 297). In either case, imagery is taken to occur when processes associated with perception take place in the absence of the relevant stimulus.

The most commonly discussed form of mental imagery, visual imagery, thus occurs when there is a mental process of the same type as occurs in actual vision, but without an external stimulus. But the same thing can clearly happen for other sensory modalities. In the case of motor imagery it is kinesthetic or proprioceptive processes that are generated. It is further helpful to consider that motor imagery can fit the three intuitive features of imagining - directedness, activity, and phenomenal character - that Amy Kind proposes as a part of her argument that imagination involves visual mental imagery (2007: 89-95). First, motor imagery is directed because there is some possible action in the world that the motor image is "about." Motor imagery is also straightforwardly active (one is doing something when one imagines), and perhaps more so than visual imagery. According to Jeannerod, for instance, "imagined actions are indeed actions in their own right," largely because our bodies go through many of the same processes (such as increases in heart and respiration rate, and activation of motor pathways to relevant muscle groups) that they undergo during actual action, though in ways that can end up being blocked or inhibited (2006: 39; see also Anema and Dijkerman 20I3: I00I03). He thus thinks of motor images as being simulations of actions that involve "dynamic changes in the content of the image over time, corresponding to the unfolding of the action which is being imagined" (2006: 24). The way in which motor images are active also suggests that they have an experiential character; insofar as

6. The title of Chapter Two of Jeannerod (2006) is "Imagined Actions as a Prototypical Form of Action Representation." 
there is something it is like to perceive the kinesthetic contents of an actual action, there is something it is like to undergo the simulated action. ${ }^{7}$ Two caveats are in order here, however. First, as Kind notes, the experiential character of imagery is typically weaker than experiential character of the perceptions the imagery simulates (2007: 94-95). Frequently, perception and imagery are taken to lie on a sort of continuum, with qualities like vividness, determinacy, and intensity weakening as one moves from perception to imagery. ${ }^{8}$ Second, and more importantly, it must be noted that motor imagery can remain implicit and unconscious. This second point will be further discussed below.

Motor imagery can be completely detached from execution of the action, and this is perhaps the most common way of thinking of motor images. For instance, motor imagery is often used by athletes to practice for competition prior to and separate from the actual event. A downhill skier might imagine going through the entire race as a part of her race preparation, for instance. Such cases are consciously experienced and evince at least some measure of conscious control. Cases like this also often combine motor imagery with visual imagery; for instance, the kinesthetic sense of the movements involved in skiing would be combined with visual images of the course being skied.

For the purposes of this paper, however, it is important to note instances where motor images are preparatory for action. Jeannerod argues, for instance, that motor images are "widely used in preparing actions in everyday life" (2006: 28). As noted above, motor images involve simulations of actions, insofar as the same bodily processes that are involved in the actual action are also involved in motor imagery. In examples like the ski practice case noted above, those processes are inhibited, and remain at the level of imagery. But in some cases the processes are not inhibited in such a manner, and thus motor imagery amounts to a sort of preliminary, covert rehearsal of an action that follows. Such preparatory motor imagery

7. Moran, Guillot, MacIntyre, and Collet (20II: 233-234) argue that simulated movements are equivalent to real movements at "the neural and/or mental representational levels, not at the phenomenological level", and furthermore take the view that motor imagery is experienced as being like action to involve a category error. Part of their argument for this is that "imagining a boxing match or a marathon does not make one feel as tired or as sore as if one actually competed in such events," but all this shows is that the experiences are not identical (and surely no one ever thought that they were). Furthermore, Jeannerod (2006)--to whom Moran et al. (20I I: 25-26) appeal--uses the firstperson reports of subjects undergoing motor imagery tasks as a part of his evidence to establish the equivalence between motor imagery and actual action in a manner that suggests some phenomenal similarity.

8. For more discussion of the relation between perception and imagery see Thomas (2014: \I.2), which helpfully summarizes the issue and provides references to further discussion. The view that imagery is a weakened perception has a long history (for example, Hobbes (I996: I 5-I6) referred to imagery as "decaying sense" and Hume (2007: I2-I3) took imagery to copy perception but with less force and vivacity), and some version of it is implied by the view that imagery occurs when sensory processes are engaged absent a stimulus. The specific ways in which different kinds of imagery are "weakened" remain to be spelled out, however.

Ergo • vol. I, no. $7 \cdot 2014$ 
can be non-conscious, as is suggested by various empirical results. For example, in one experiment (Frak, Paulignan, and Jeannerod 200I) subjects were asked to quickly judge, via verbal report, whether the task of grasping and emptying a container of water would be easy, hard, or impossible. The container was then oriented in different ways that would potentially alter the difficulty of the task. Subjects' response times varied according to the orientation of the object in a manner that closely corresponds to the time it would take to actually execute the action (i.e., it would take longer to respond "difficult" when the object was positioned in a manner that would make it harder to grasp). The varying response times are taken to show that the subjects are facilitating the judgment by simulating the action (with the more difficult action comes a longer simulation). But a crucial point here for Jeannerod is that subjects were asked to quickly report the judgment (thus reducing the chance that they would have time to consciously consider the matter) and were not instructed to consciously imagine the action (2006: 28). Due to this, he interprets such experiments as showing that people engage in non-conscious preparatory simulations of actions. ${ }^{9}$

A terminological issue arises here. It is common to take the term "imagery" to refer specifically to a class of conscious experiences. For example, Moulton and Kosslyn (2009: I 278) generally agree with Jeannerod that imagery can involve action simulation, but argue for a separation between simulations that use imagery, which they take to be explicit and conscious, and those that are implicit. In fact, Jeannerod himself seems to treat the matter this way in some of his earlier works on the subject (e.g., Jeannerod I994: I90). In later works, however, he selfconsciously departs from the common understanding of imagery as necessarily consciously experienced: "whereas the term 'motor image' classically refers to explicit or conscious representation of an action (imagine yourself running or raising your hand), the same concept also includes other, implicit or unconscious, aspects of the same phenomenon" (Jeannerod and Frak I999: 735; see also Jeannerod 2006: 28). ${ }^{\text {Io }}$ The reason for this terminological choice is that non-conscious motor simulations are functionally the same as the motor simulation that is consciously experienced (see, i.e., Jeannerod and Frak 1999). Whether or not the simulation is consciously experienced depends upon conditions including time constraints (simulations can happen too quickly for conscious experience to arise) and whether or not the simulated action is successfully carried out or inhibited (Jeannerod 2006:

9. In this discussion Jeannerod references Frak, Paulignan, and Jeannerod (200I) and de'Sperati and Stucchi (I997). In a response to Jeannerod (I994), Rizzolatti (I994: 220) provides different support for the idea that there are non-conscious motor images by referencing an experiment that measured the neural activity of monkeys who watched experimenters engage in grasping movements.

Io. It should be noted that Jeannerod (2006) is not completely unambiguous in this regard. For example, on page 28 he refers to "implicit motor imagery" which is non-conscious, but also refers to such non-conscious simulations as being "in contradistinction to motor imagery proper." On balance, though, he treats the non-conscious simulations as being a part of motor imagery overall.

Ergo $\cdot$ vol. I, no. $7 \cdot 2014$ 
ch. 3). Whether or not such conditions actually come into play, non-conscious imagery is in principle potentially consciously experienced; thus the notion of nonconscious imagery does not move entirely away from the standard understanding of the term imagery. This suggests that the phrase "implicit motor image" is particularly apt; what is implicit in this case can be made explicit.

To summarize the foregoing points, motor imagery can come into play when one readies oneself for action by implicitly simulating the action just prior to its performance. But motor imagery does not only prepare the body for action, it also helps regulate bodily action during performance by playing a role in the use of forward models or emulators (Jeannerod 2006: 20; see also Grush 2004, who favors the latter term). Forward models are simulations that enable the body to predict outcomes of actions prior to sensory feedback (for an accessible overview see Wolpert and Flanagan 2009: 295-296). Clearly, during bodily action one can adjust one's movements on the basis of sensory feedback (i.e., if an obstacle is in my path while I am walking, I can change course). But sensory feedback is slow, and alone would not allow for the kinds of quick, fine-grained adjustments made in cases of relatively fast skilled action (soccer playing or organ playing, for instance). Forward models allow for quicker control by putting forward a pre-action plan (motor images can serve as that plan) that can be used to monitor bodily outputs (i.e., as we act our actions can be compared to the plan). ${ }^{\text {II }}$ Forward models are further linked to the kind of skilled action found in the soccer and organ examples because they are enriched through the learning of a skill, which thus enables more competent performance (see Wolpert et al. 20 I I: 739-742). Skilled performers can deploy more complex motor imagery that both prepares for and helps regulate actual skilled performance (for a similar view see Van Leeuwen 20I I).

Insofar as the above description distinguishes between forward models/emulators and the sensory feedback they precede, this way of construing action control would seem to separate action from perception. But the opposite is actually the case. As Grush puts the point, "the perceived environment is the environment as made manifest through the organism's engagements, because the emulator that supplies the perceptual interpretation is an emulator of the agent/environment interactions" (2004: 393). Forward models provide predictions that anticipate actions in a way that runs ahead of slower sensory feedback. This does not mean, however, that forward model regulation is separated from sensory feedback. Forward models are not only integrated with various sensory feedback loops such that their commands can be adjusted, but they also enable filtering of sensory

I I. For more detail on these points, see Grush (2006: 378-380) and Wolpert, Diedrichsen, and Flanagan (20II: 740-742). The way a forward model works is more complicated than I have described it here. One important point to note is that the forward model is not necessarily compared to our actions directly, but rather to an efference copy, or an internal copy of motor outputs that is created as the outputs occur.

Ergo $\cdot$ vol. I, no. $7 \cdot 2014$ 
information so those feedback loops can better inform the system (Wolpert et al. 2OII: 740-742). Thus the perception that results is the product of a thoroughgoing combination of sensory information and motor planning.

\section{Fitting Motor Imagery into Merleau-Ponty's Views}

Given this initial description of the motor imagery view, it is prima facie problematic to say that it can fit with Merleau-Ponty's views. The first potential problem is that it is unclear if Merleau-Ponty would agree with the conception of imagery on which the motor imagery view rests (i.e., that imagery is quasi-perceptual and occurs when perceptual processes are engaged absent a stimulus). In his early works Merleau-Ponty often seems to stress that perception and imagination are discontinuous. ${ }^{22}$ For example, in Phenomenology of Perception he states that we "are never geared into the imagination" as we are in perception (20I2: 338), and in his 1949-50 lecture course "Structure and Conflicts in Child Consciousness" he argues that "the image is not an enfeebled perception. It is not susceptible to being "observed" or examined point by point like a perceived thing" (20I0: I76). The key point in each of these passages is that imagery differs from perception insofar as one cannot inspect the image from varying perspectives in the way that one can further inspect a perceived object. Given this, imagery and perception must differ in kind, rather than merely in degree. Following this point, Merleau-Ponty denies that the image is a kind of "internal" mental object, which can be inspected internally in the way that a perceived object can be inspected "externally."

Merleau-Ponty's views on imagination are much more amenable to the contemporary "quasi-perception" view than these passages suggest, however, and this can be seen by examining both the contemporary view and Merleau-Ponty's view further. First, it must be noted that the quasi-perception view of imagery does not have to imply that perception and imagery are identical (but for the absence of the external stimulus). The quasi-perception view holds that some of the processes that perception engages are engaged by imagery, so perception and imagery are functionally similar (not identical). ${ }^{13}$ And, as was seen above, enactivist views, which would reject the idea that mental images are internal objects, still hold to a version

I 2. To a large extent Merleau-Ponty is following Sartre's earlier studies on the imagination in this regard. On this point see Steeves (2001: 370-372).

I3. Also, some contemporary imagery research seems to go against Merleau-Ponty's claim that imagery cannot be examined from different perspectives. Most pertinent in this regard is research into "mental rotation," which shows that people can imagine objects that they mentally rotate and "view" from different perspectives. One way of interpreting this research is to construe mental rotation in terms of exactly what Merleau-Ponty wants to deny; i.e. one entertains an internal picture that one examines from different perspectives. For a concise overview of this research see the supplement on "Mental Rotation" to Thomas (2OI4). But such an interpretation is not obligatory; see Thompson

$$
\text { Ergo } \cdot \text { vol. I, no. } 7 \cdot 2014
$$


of the quasi-perception view. For Merleau-Ponty's part, he does say things that fit with this view. For example, he says that when one imagines a body part, one feels a "quasi-sensation" (2OI 2: 245). Later in Phenomenology of Perception in a discussion of thinking through geometrical problems using a triangle, he compares using an imaginary triangle to using a "sensible" triangle and notes that the imaginary triangle "is at least virtually situated in my perceptual field" (20I 2: 405). On balance, Merleau-Ponty seems to support something like the enactivist version of the quasi-perception view.

A bigger problem for fitting the motor imagery view with Merleau-Ponty's thought is the fact that (as seen in the previous section) motor imagery and forward models/emulators, are often described as being representational. ${ }^{\mathrm{I} 4}$ MerleauPonty's views, on the other hand, are usually taken to be paradigmatically antirepresentationalist (e.g., Dreyfus 2002a; Gallagher 2008b: 360-364). Of course there are large debates over the nature and status of "representations." And specifically within the philosophical and scientific discussions that are closest to MerleauPonty's concerns (i.e., "embodied cognitive science") there is a robust debate over whether the concept "representation" should be revised and retained or jettisoned completely (for a prime example of the "revise and retain" view, see Clark I998: ch. 8; for a prime example of the "jettison" view, see Hutto and Myin 20I3). It is beyond the scope of this paper to work through these debates and to properly situate Merleau-Ponty's thought within them. But we can fix on Merleau-Ponty's critical points that are most important for the present discussion, and show that the conception of motor imagery proposed in the previous section does not have to run afoul of these criticisms.

One can find criticisms of representationalist views throughout MerleauPonty's early work, but it is important to determine what, exactly, he is criticizing. One can start with two basic criticisms. First, he rejects the idea that skilled actors consciously engage in mental preparation for their actions. For instance, the soccer player is "unaware" of the way in which the skilled actions are initiated and guided (for other passages that directly link representation to conscious thought, see, e.g., Merleau-Ponty I983: 63; 20I2: I38-I39). Furthermore, in rejecting representationalist theories of action Merleau-Ponty claims that "consciousness is originally not an 'I think that,' but rather an 'I can'" (20I2: I39). This amounts to more than a rejection of consciousness in action, however. Consider how close MerleauPonty's language is to Gilbert Ryle's terminology ("knowing that"/"I think that" and "knowing how"/"I can"). Ryle is not just arguing against action requiring

(2007: 299-30I) for a discussion of mental rotation research in the context of an enactivist theory of imagery.

I 4. As seen in note 6 above, Jeannerod construes motor imagery as being a species of representation. Also, Grush presents his theory of emulators precisely as being a (better, he thinks) theory of representation; this point is made most directly in Grush (I997).

Ergo $\cdot$ vol. I, no. $7 \cdot 2014$ 
conscious thought. In The Concept of Mind (2009: ch. 2) he more generally criticizes intellectualist views that take action to depend on propositional states.

Though Merleau-Ponty does not use the language of "propositional states," he would reject propositionalist views of action. A primary reason for this is that standard propositionalist views hold that knowing how to act skillfully requires knowledge of a fact/true proposition (see Stanley 20 I I: vii). As Jason Stanley puts the point: "acting with skill is action that manifests an agent's knowledge of facts" about that skillful action (2OI I: viii). ${ }^{15}$ For Merleau-Ponty, skilled action would be too context dependent and too tied into a holistic network of further actions to be adequately specified in terms of discrete facts. This leads him to claim that when it comes to action, "I possess the conclusions without the premises being given anywhere" (1983: 30), which is to say that we can complete actions without having to somehow possess individual facts or propositions (the "premises") about how the action is completed. ${ }^{\mathrm{I}}{ }^{6}$

These two criticisms (against conscious thought and against propositionalism) do not apply to the motor imagery view. First, the preparatory motor images that are important for the present view are precisely non-conscious and not overtly considered or ratiocinated. This point might be obscured somewhat by some of the language used. For example, the discussion of forward models/emulators above refers to motor imagery as playing a role in action planning. The act of putting together a plan for an action sounds like a conscious activity, perhaps of the type mentioned above in the downhill skier example. But the action planning connected with forward models is not conscious; it is the activity of a sub-personal mental process. There is no need to construe the preparations that go into our bodily actions as conscious or thought out.

But what of the criticism of propositionalist views of action? It should be noted that even among representationalist views there is debate concerning whether any mental imagery is propositional in nature, with prominent contemporary views

I 5. It is worth noting, though, that Stanley's propositionalist view of skilled action does not depend on the propositional states being consciously entertained (2OII: I9-2I). This possibility is connected to the idea that while "knowing that" and "knowing how" are both species of the same thing (propositional knowledge) they can differ according to the relevant "ways of thinking." This view, which exploits the Fregean idea that propositions can fit differing "modes of presentation," holds that knowing how exploits "practical ways of thinking" (see 20II: I22-I30).

I6. In the broader passage cited here Merleau-Ponty (I983: 29-30) argues that "intelligence" does not intervene in common bodily actions. Part of his reasoning is that intelligent thought would take too long, and he is clearly thinking of conscious reasoning here. But he also argues that intelligence would require the action to be divided, untenably, into determined thinkable parts. It should be noted that "intelligence" (which he puts in scare quotes in this passage) is equated with intellection or reasoning, and he does not mean to reduce bodily action to mere reflex. For example, a few pages later he refers to "a directed activity between blind mechanism and intelligent behavior which is not accounted for by classical mechanism and intellectualism" ( $1983: 40$ ). This is of course a major theme of his early work in general.

$$
\text { Ergo •vol. I, no. } 7 \cdot 2014
$$


rejecting propositional representation in favor of "depictive representation" (such a view is prominently associated with the work of Stephen Kosslyn; e.g., Lewis, Borst, and Kosslyn 2010). Setting this debate aside, it would seem that motor images would not be propositional in nature because of their distinctly motor character. Motor images are simulated actions rather than facts about actions. Furthermore, the motor imagery view fits with the Merleau-Pontyian point noted above regarding context dependence. Jeannerod, for instance, rejects the idea that motor images contain "pre-organized units of action" (2006: I2). This is because motor images need to fit changing action contexts and Jeannerod takes them to involve "dynamic procedures" (2006: I34). Engaging in motor imagery would thus involve manifesting such dynamic procedures rather than knowledge of facts about action. None of these points settle any arguments about the representational status of motor images, but it should at least be clear that we need not take arguments against propositionalism to be arguments against the motor imagery view.

Beyond the criticisms of conscious representation and propositionalism, Merleau-Ponty also rejects the idea that there is some sort of internal objective depiction of our actions (the plan) that is separated from the specific contexts in which we act. For example, early in The Structure of Behavior he criticizes scientific views that conceive of animal behavior in terms of "physiological representations" which are, to quote the psychiatrist Paul Schilder, "first given as a nucleus from which the totality of the movement is subsequently differentiated" (Merleau-Ponty I983: 30; Schilder I923:65). It is the case that a variety of views developed in the 2oth Century held, like Schilder's, that actions are represented by static formulae, schemas, or models that are stored internally, and which contain, in the words of the Russian physiologist Nicolas Bernstein, "like an embryo in an egg or a track on a gramophone record, the entire scheme of the movement as it is expanded in time" (Bernstein I967; quoted in Jeannerod 2006: I I). For MerleauPonty such static motor schema are not appropriately context sensitive and require an untenable abstraction from the contexts in which actual actions occur (see, e.g., 20I2: I4I). ${ }^{\mathrm{I} 7}$ Action cannot be explained in terms of a representation that contains the totality of the action prior to its enactment, because actions only come about within specific contexts that cannot be entirely specified beforehand.

The motor imagery view does not fall prey to this criticism either. As we saw in the discussion of propositionalism, Jeannerod favors a dynamic conception of motor imagery because "the same movement is rarely, if ever, replicated twice . . . schemas should be plastic and adaptable rather than fixed" (2006: I2). While

I7. Merleau-Ponty is critical of conceptions of "motor memory" (2OI2: I4I), while memory does play an important role in Jeannerod's theory. But the most important point Merleau-Ponty is making is that memory does not provide a complete or static depiction of the movement. MerleauPonty's view thus does not depend on removing memory entirely from the process of preparing for and regulating our actions. 
preparatory motor images might draw partly on memory, they are primarily "assumed to be embodied in the wiring of the motor system: they are better defined as dynamic procedures than as pre-organized structures" (2006: I34). These dynamic procedures are made up of "functional rules for assemblage, including the biomechanical constraints, the spatial reference frame, the initial positions, the forces to apply, etc.” (Gallagher 2008a: I79; Gallagher is interviewing Jeannerod). So motor imagery is derived not from static models but from stored abilities to engage in certain procedures that are somehow "wired" into the motor system (and, as we will see below, this enables them to dynamically engage with the action environment).

In this regard Jeannerod's view is quite similar to Merleau-Ponty's description in Phenomenology of Perception of the acquisition of motor habits. The organist is able to play the new organ without having to draw up a plan because the organist has acquired the habit of organ playing. Merleau-Ponty does not have much to say about the physiological bases of motor habits. But he does describe habitual action as "engaging in the world through stable organs and preestablished circuits," which sounds somewhat like the idea that dynamic procedures are wired into the body (2012: 89). ${ }^{18}$ Our ability to non-consciously simulate an action could be a key element of our ability to engage in habitual action. ${ }^{\text {I9 }}$ Merleau-Ponty is further not opposed to the idea that in action we draw on elements that are somehow taken on board by our bodies. This is seen in his use of the terms "sediment" and "sedimentation." For example, in The Structure of Behavior he notes that "the body in general is an ensemble of paths already traced, of powers already constituted," and in a note to this passage connects this to the "cultural body" which is the sedimentation of its spontaneous acts" (I983: 210, 249). The "cultural body" thus "sediments" these already traced paths, and it is not hard to find in this the idea that the processes associated with actions we have previously practiced become embodied in us. ${ }^{20}$

Importantly, Merleau-Ponty emphasizes that motor habits and sedimentation do not tie us to a pre-established outcome. Habits engage our ability to act in new situations; Merleau-Ponty says "it is as though our body comprises two distinct

I 8. The idea that dynamic procedures of the type Jeannerod discusses are wired into the body fits best with the reference to "preestablished circuits." When Merleau-Ponty refers to "stable organs," he means elements of our "bodily nature," i.e. aspects of our given physiology that allow for bodily action to occur. Jeannerod of course also includes this aspect in his discussion, i.e. in his consideration of biomechanical constraints (2006: 26-27).

I9. In commenting on Grush (2004), Schubotz and Yves von Cramon (2004: 4I4-4I 5) explicitly make such a connection between imagery simulation and habit.

20. Although the idea clearly includes the point being made here, it must be noted that there is much more to Merleau-Ponty's discussion of sedimentation than this. In fact, the references to sedimentation in Phenomenology of Perception have less to do with bodily actions--which are predominantly discussed in terms of habit--than they do with the embodying of conceptual and cultural elements. He also speaks of sedimentation as happening in the world rather than in our bodies, insofar as we shape our environments to support our habitual actions.

$$
\text { Ergo } \cdot \text { vol. I, no. } 7 \cdot 2014
$$


layers, that of the habitual body and that of the actual body" and "the habitual body can act as a guarantee for the actual body" (20I 2: 84). In this case the "actual body" is the body as it engages in actual action contexts in the here and now. That habits enable us to engage in new contexts is partly explained by the point mentioned above that they should be thought of as dynamic procedures. One must go farther than this, however, and note that the habitual and actual are tied together in what Merleau-Ponty calls "the double moment of sedimentation and spontaneity" wherein sedimented habits "feed off my present ... at each moment; they offer me a sense, but this is a sense that I reflect back to them" (2OI 2: I32). ${ }^{2 \mathrm{I}}$

The idea that embodied habits can be tied into present contexts in such a way that the present contexts "reflect a sense back into them" fits quite well with the way in which motor imagery operates in forward models/emulators. As mentioned, above, forward models are linked together with sensory feedback such that the two loop together. In emphasizing the importance of seeing motor regulation as based on the combination of forward model prediction and sensory feedback, Shaun Gallagher compares this view both to Husserl's and Merleau-Ponty's views on the temporality of experience (2005: I 89-205). ${ }^{22}$ There is a protention-retention (to use the Husserlian terminology) movement in the activity of the forward model, which is to say that the elements of the plan that are moved forward into the action prepare for the incoming sensory information that is then retained for use in updating the forward model.

The role of motor imagery in forward models also brings up a comparison with Merleau-Ponty's notion of "the function of projection" in action (2OI 2: I I4I I 5). In his discussion of the patient Schneider, Merleau-Ponty notes (following Kurt Goldstein) that one of Schneider's problems is that while he can engage in "concrete" movements which are tied directly to the given context (i.e., using a given hammer to drive a given nail) he cannot easily engage in "abstract" movements which are not tied directly to any given situation (i.e., pretending to hammer a nail) (20I2: IO5-II4). Merleau-Ponty interprets the lack of ability in abstract movement to be tied to a general inability on the part of Schneider to "invert the natural relation between my body and the surroundings" and to thus take one's environment as a situation which allows for the possible actions that one intends,

2I. One should note that in this passage Merleau-Ponty is actually discussing sedimented conceptual knowledge, which is implicitly available for us in our occurrent thinking about the world. The general point holds regarding motor habits as well, however.

22. Gallagher (2005: I 89-205) also relates the sensory feedback element of action control to J.J. Gibson's views, and uses a description of the actions of schizophrenics to show that sensory feedback alone, without forward model control, is incapable of regulating normal action. This is perhaps a reason to think that Gibsonian psychology, and its concept of affordance, cannot adequately explain the Merleau-Pontyian phenomenology of skilled action, because it cannot completely explain the way in which we anticipate the skilled actions the environment affords. 
rather than being merely guided by that environment (201 2: I I 5 ). Schneider can be guided by the world but cannot feed possibilities forward into the world.

Merleau-Ponty uses the metaphor of "projection" to describe our ability to find our possibilities for action in the environment; we "project" possibilities upon the world. ${ }^{23}$ It is not difficult to think of the use of motor imagery in forward models in the terms of such projection. When one engages a preparatory motor image that then feeds forward into an emulation that predicts and regulates action, one is precisely not merely engaging in concrete action. One is rather engaging with an action that one takes to be possible and thus fitting a plan for that action onto the action scene. And, of course, the very language of "motor imagery" and its connection with imagination fits well with Merleau-Ponty's point here; imagery is capable of swinging free of the "ready-made or fixed world" (2012: I I 5).

Of course the foregoing considerations do not prove that Merleau-Ponty would himself accept the motor imagery view. But it has been shown that the motor imagery view does not fall prey to some of Merleau-Ponty's key criticisms of representationalism, and that the motor imagery view fits well with some of Merleau-Ponty's main concerns. This should be enough to show that it is plausible to fit the motor imagery view with a broadly "Merleau-Pontyian" way of thinking about action. It should also be noted that the vexed issue of whether or not motor imagery should be described in the language of representation is far from settled, but the present investigation should be able to proceed without that question being definitively answered. ${ }^{24}$ The big question for the present investigation is whether it is plausible to think that motor imagery can affect perception such that opportunities for action can show up in perception.

\section{Motor Imagery's Effects on Perceptual Experience}

While the previous section establishes that contemporary theories of motor imagery can fit with many of Merleau-Ponty's overall concerns regarding skilled action, the question of whether or not motor imagery can support his phenomenological descriptions has not yet been answered. Recall that Merleau-Ponty indicates-and scholars like Dreyfus and Romdenh-Romluc further emphasize-that we directly

23. For a discussion of this issue see Romdenh-Romluc (2007). I would propose that the use of motor imagery and forward models could help explain the phenomenon of "reckoning with the possible" that Romdenh-Romluc considers there.

24. It is quite likely that the key elements of the motor imagery view can be couched in both representationalist and anti-representationalist vocabularies. For example, Chemero (2009: 60-65, I 80-I $8 \mathrm{I}$ ) discusses the extent to which emulators (the existence of which he takes to be empirically well-supported) can be described in representationalist and anti-representationalist frameworks. 
perceive opportunities for action. What really needs to be shown here is that such phenomenological descriptions are empirically plausible and can potentially be explained by the effect that motor imagery has on our perceptual experience.

This point will be argued for in this section in two ways that will correspond to the two subsections below. First (in subsection 3.I) it will be argued that we have good reason to think that imagery can influence perception to create unified experiences. Second (in subsection 3.2) it will be argued that there is good reason to think that planning for action can affect perception, which gives us further reason to think that motor imagery specifically can affect perception. Put together, these two arguments will provide strong support for that thesis.

\section{I Imagery's Effect on Perceptual Experience}

There is abundant reason to think that visual imagery can influence visual perception. It is possible, for instance, to consciously augment visual experience with imaginative contents through the process Robert Briscoe terms "make-perceive"; Briscoe gives the examples of standing in an empty room and imaginatively arranging furniture in it or looking at the night sky while one imaginatively "draws" lines to connect the stars in a constellation (2008: 479; 20 I I: I 53-I 54; forthcoming). As another example, studies show that subjects can combine visual images with occurrently perceived figures in order to determine facts about a combined image. The authors of a recent study of this type conclude: "mental images preserve structural information of the pattern they represent, and can be integrated with percepts to create a single composite representation" (Lewis, Borst, and Kosslyn 2010: 270).

One can also find examples of similar effects in perceptual modalities other than vision, and examples where the influence is cross-modal. Briscoe mentions, for instance, that rock climbers might augment their visual experience of the climbing surface with motor imagery of possible future hand-or-footholds, or sculptors might augment their visual experience of a block of marble with motor imagery of possible sculpting actions (forthcoming). ${ }^{25}$ In each case the purpose would be (as in the above furniture arranging case) to evaluate future actions. Studies also show that stimuli in one modality can elicit experiences in another modality; for example, visual perception of silent lip reading can activate neural areas associated with hearing in a manner that might connect with the feeling that one is hearing something (Spence and Deroy 2013: I58). Also, in one study subjects presented

25. These cases might also involve visual imagery; i.e. the climber might imagine seeing a hand on a rock or the sculptor might imagine what the marble would look like when sculpted in a particular way (this seems especially likely in the latter case). But insofar as the climber and sculptor are engaged in the activity while doing the imagining they would simulate the actions and thus engage in motor imagery as well. 
with an audiovisual recording of the ear of a dummy being stroked by a brush reported feeling that their own ears had been tickled (Kitagawa and Igarashi 2005; cited by Spence and Deroy 20I3: I 58). Spence and Deroy (2013) interpret these examples as being instances of cross-modal imagery where perceptual experience in one modality causes imagery in another modality.

In each of these examples, genuine perceptual processes (i.e., processes connected to an external stimulus) are combined with perceptual processes in other modalities that are not directly connected to an external stimulus (i.e., imagery). And in some cases this involves motor imagery. Further consider Briscoe's rock climbing example. The climber has genuine visual perception of the rock to be climbed and at the same time engages imagery of the possible ways in which that seen rock might be gripped or held; thus visual perception and motor imagery are combined. Furthermore, it is easy to think of the motor imagery in this case as being preparatory; the climber is using imagery to plan for the climbing actions to come. Thus this example fits well with much of the discussion of motor imagery in sections I and 2 above. But there is one massive difference: the subject is aware of consciously having combined or hybrid perceptual and imaginative experiences. In all of Briscoe's "make-perceive" examples and in the Lewis, Borst, and Kosslyn (20IO) example, subjects consciously invoke imagery that is added to perception such that the two are clearly kept apart (one would not, for instance, report oneself as literally "seeing" the imagined furniture in the empty room). The examples discussed by Spence and Deroy are different in that perceptual experiences induce imagery, but they are clear that in these cases "people typically do not mix up their experiences ... with genuine percepts" (2013: I62).

But there is also empirical evidence that shows that imagination and perception can combine such that the subject does not distinguish the elements in experience. Perhaps the most famous example of this is the so-called "Perky effect" wherein visual experiences are mistaken for imagined experiences. In C.W. Perky's original experiment, subjects were told to fixate on a blank screen and imagine objects like a banana or leaf. Unbeknownst to the subjects, visible corresponding objects were then projected on the screen, but the subjects reported having only imagined the object (for a discussion see Waller, Schweitzer, Brunton, and Knudson 20 I2). In order to support an argument that imagination and perception can combine to form a single experience, Fiona Macpherson reports on another similar study:

Segal ... performed an experiment like Perky's in which she asked subjects to imagine the skyline of New York. An image of a tomato was projected onto the screen. Observers didn't report the tomato image but several reported imagining seeing New York at sunset. Thus, we have examples where perceptual elements and imaginative elements combine to produce the phenomenal character of what seems to the subject to be one state - be

$$
\text { Ergo } \cdot \text { vol. I, no. } 7 \cdot 2014
$$


it really a perceptual experience, really an imaginative experience, or some amalgam of the two. (2012:52)

The fact that the subjects reported imagining a red sunset but did not report seeing a tomato supports the idea that visual experience can non-consciously have an effect on imagination, and that the red visual element combined with the imagined element to, as Macpherson argues, create one experiential state.

A bit more needs to be said regarding the idea that "one experiential state" is created. Perky's results are often interpreted as showing that perception and imagery can be so similar experientially that they are wholly indistinguishable (i.e., imagining a banana can be identical to a veridical perception of a banana). See, for example, Kind's claim that "Perky's experiment shows that, in some cases at least, perceiving feels exactly like imagining" (200I: 94; for criticisms of this type of interpretation of Perky's results see Casey 2000: I47-I 5 I and Hopkins 2012). The Perky effect tends to be interpreted in a different manner in the empirical psychological literature, however. As Waller et al. (2012: 293) note, subsequent experiments (including Segal's that Macpherson reports) have led Perky's idea to "become identified primarily with the idea that perceptual detection or discrimination is interfered with by concurrent imagery tasks." They go on to note that a body of research following Perky has considered the ways in which imagery might facilitate rather than interfere with perception. Reeves and Craver-Lemley (who are prominently associated with the "interference" interpretation) suggest that while it seems clear that there is an effect, the exact mechanism of the effect is unclear (2012: 6-7).

Given this, we might say that the lesson of Perky's (and subsequent) experiments is not that imagery and perception can be exactly alike, but that imagery can affect perception in ways that subjects do not consciously notice. "Single experiential state" would in this case just mean that one does not consciously discern the elements that are properly perceptual from the elements that derive from or are affected by imagery. For example, some of Segal's results are taken to show that the detection threshold for perceptual stimuli was raised by the concurrent imagery task (e.g., Segal and Fusella I970: 463-464; see also Waller et al. 20 I2: 293). So, on this interpretation, when the subjects were asked to imagine the New York skyline, the operation of that imagery task made it more difficult for them to consciously detect the faint tomato image, such that they mistook the redness of the tomato for a sunset in their imagery. ${ }^{26}$ This is, of course, specifically an instance of imagery interfering with visual perception. But, as noted above, the current re-

26. Segal does not herself provide such an interpretation of the skyline/tomato case. Her description of that case is very brief, and is talked about in general terms, referring merely to the stimulus having an effect on the image (I972: 206-207). The interpretation given here is consistent with Segal's thoughts on such cases, however. 
search holds that imagery could facilitate perception via "Perky-style" influences as well.

In the Segal experiment, the single experiential state is taken by the subjects to be an instance of imagery; they report imagining the sunset over New York and do not recognize the visual contribution of the projected tomato. But we can find other instances of imagery affecting perception where the experiential state is taken to be visual, with subjects not recognizing the contribution of imagery. This is important, because that is the kind of situation that would have to be at play in the Merleau-Pontyian cases. For example, Kosslyn and Sussman argue that imagery can supplement visual recognition tasks in this manner; "when the generated image matches the input image, we simply experience seeing the object" (1994: I036). Their argument is based partly on the fact that successful computer vision programs have been created that use representations that are functionally analogous to stored imagery to supplement shape matching tasks (thus making it plausible that such a model could explain human vision). But they also hypothesize that such a use of imagery can explain experiments where human subjects engage in perceptual shape matching tasks. For example, subjects who were asked to determine whether a partially occluded figure was a square provided correct answers much more quickly when the figure matched a previous stimulus. These results fit what would be "expected if subjects formed an image of the previous stimulus and used it to recognize successive stimuli" (Kosslyn and Sussman I994: I035-I036).

It has also been recently argued that certain instances of the "memory color effect" (wherein one perceives an object to be its typical memorized color-red for a heart figure, for instance-even though it is not actually that color) can be explained by hypothesizing that imagery affects visual perception in a manner that is unknown to the perceiver. ${ }^{27}$ Regarding a particular memory color effect case, Macpherson argues that subjects matched orange cut outs of characteristically red figures to red backgrounds because of the influence of imagery:

[In this case] the first step would be that a subject's knowledge that the cutout was of a shape that is of a characteristically red object would affect the subject causing them to imagine a red object, or generate the process that would typically produce an imaginative experience of a red object. The second step involves the phenomenal character of this imaginative state, or the imaginative process that typically would produce it, interacting with the phenomenal character of the visual experience of the orange cutout shape, or the perceptual process which would typically yield such a visual experience. The result is an experience as of a reddish-orange colour. (2OI 2: 55)

27. For a recent paper which both provides a good overview of the memory color effect, and presents an experiment which purports to display the effect, see Witzel et al. 20 I I.

Ergo $\cdot$ vol. I, no. $7 \cdot 2014$ 
On Macpherson's explanation the subjects had one single perceptual experience that combined the imagined red and occurrently perceived orange without the subjects realizing that the two elements combined.

Macpherson interprets the experiment as showing that imagery and perception "produce one state with phenomenal character whose nature has contributions from both the imaginative and perceptual processes" (2OI2: 55). Following the remarks on the interpretation of the Perky effect above, we can take Macpherson's claim to mean that imagery has an unnoticed, non-conscious effect (via interference, facilitation, or something else) on the phenomenal character of the perception such that the two cannot be teased apart by the subject in the overall experience. Hypothetically, for instance, it could be the case that imagining the typically red object interferes with color perception such that what would otherwise be seen as orange is seen as orange-red. ${ }^{28}$ This would not be a case of visual experience that "feels exactly like" imagery (or vice versa); it would be an instance where imagery processes somehow modulate the character of the visual experience (without the subject being cognizant of the imagery effect).

So far, it has been shown that imagery in multiple perceptual modalities can affect or combine with occurrent perception. This includes the suggestion that motor imagery can combine with visual perception as in the rock climber and sculptor cases (albeit in ways that keep the imagery and perception consciously apart). Evidence has also been given to show that imagery and perception can combine in such a way that they result in a unified experience where one does not distinguish the effects of imagery from the visual experience (as Kosslyn and Sussman (I994) put it, we can "just see the object," instead of taking there to be a hybrid experience). But this latter evidence focuses solely on visual imagery and visual experience.

\subsection{Motor Activity's Effect on Perception}

The argument of 3.I thus does not fully support the current thesis, because it does not fully show that motor imagery can affect visual perception in a manner that results in a unified experience. This section will show that there is good reason to think that action can influence visual perception, and when combined with the results of 3.I this will provide support for the current thesis.

There have been numerous recent studies that purport to show that visual perception of an environment can be altered by the manner in which one engages in particular actions in that environment. In particular, the perception of spatial

28. Note that this is not a hypothesis presented by the researchers in the case Macpherson discusses. They are primarily concerned with demonstrating the memory color effect rather than explaining it, and merely state that "little can be said at this time as to the mechanism by which an interaction of sensory and associative factors might occur."(Delk and Fillenbaum I965: 293)

$$
\text { Ergo •vol. I, no. } 7 \cdot 2014
$$


properties is said to be affected by encumbrance (seeing a hill as steeper when wearing a heavy backpack), use of tools (seeing a distance as shorter when reaching with a stick), or skill set (seeing a goal as bigger when one is a good kicker). ${ }^{29}$ Such studies would seem to provide direct support for the Merleau-Pontyian phenomenological descriptions. Their results, however, are too unreliable to sufficiently support the Merleau-Pontyian view. A common criticism of these studies is that the experiments are designed such that the results may be due to various beliefs the experimental subjects have about the experiments. There is compelling evidence that subjects respond to experimental demand characteristics that implicitly convey to them the experimenter's intended results, and the subjects alter their responses accordingly (Durgin, DeWald, Lechich, Li, and Ontiveros 20I I; Durgin, Klein, Spiegel, Strawser, and Williams 20I 2; Firestone and Scholl 20I4).30 Because of these problems, we should look elsewhere for empirical support of the idea that motor activity affects perception.

A recent experiment of a different kind presents more reliable evidence that planning to engage in an action can affect visual perception. Peter Vishton et al. (2007) conducted a relevant study where subjects interacted with a model of the Ebbinghaus illusion. In the most common version of the Ebbinghaus illusion, two central circles of equal size are placed close to one another, with one surrounded by larger circles and the other surrounded by smaller circles. Despite being of equal size, the central circle surrounded by smaller circles is usually perceived as larger. In the study, the central circles were three-dimensional disks that subjects could grasp, while the surrounding circles were two-dimensional images printed on a paper on which the central disks were placed. Depending on the experimental circumstances, subjects viewed the disks and circles and then indicated which was larger by verbal response, grasping the target disk, or tapping the target disk (or some combination). Overall the results showed that choices were less influenced by the illusion when the response involved an action. The authors summarize the results as follows:

29. For an overview of this type of experiment see Kirsch and Kunde (2013). Kirsch and Kunde note the standard criticisms of these experiments, but think that taken as a whole they still provide evidence that visual perception is affected by other contents.

30. Durgin et al. (20II: I080) give a good example of the effect of so-called experimental demand characteristics: "when participants were asked why they thought that they had been required to wear a heavy backpack while making slope judgments of walkable surfaces, they nearly all assumed that the backpack was intended to affect their estimates, and about half reported complying with the demand." Along with providing experiments that show the effect of design characteristics, Firestone and Scholl argue that the relevant studies run afoul of the so-called "El Greco Fallacy"; they miss the fact that the perceptual effects ought to be pervasive and thus "must cancel each other out when the means of reproduction would be distorted in just the same way as the stimulus being reproduced" (2014:39).

Ergo $\cdot$ vol. I, no. $7 \cdot 2014$ 
The experiments presented here provide evidence that action choice changes the nature of visual size perception. For every trial, the initial perceptual task of the participants was the same: choose the larger of two disks. When the participants indicated their choice with a verbal response, their perception was strongly influenced by the Ebbinghaus illusion. When their choice was indicated with a grasp or touch response, the magnitude of the illusion was significantly reduced. A similar reduction was obtained when an upcoming reaching task was described to participants. (Vishton et al. 2007: 7I8)

So we have empirical support for the idea that engaging in an action can affect visual perception.

Imagery does not play any role in Vishton et al. (2007), either in the arrangement of the experiments or their interpretation (nor does imagery play a role in the more questionable studies mentioned above, for that matter). There is an element of the study that brings it close to the discussion of motor imagery, however. Note the last sentence of the above block quote; it tells us that the effect of the Ebbinghaus illusion was reduced in circumstances where the reaching task was merely described to the subjects without them having to carry it out. Specifically, the subjects had the reaching task described to them before they gave a verbal response. Vishton et al. take this as evidence for the fact that "the studies demonstrate strong connections between action planning and perception" (2007: 7I3), and this point is further emphasized by the fact that the title of the paper references planning. This clearly suggests a connection with the description of motor imagery in section I above, where it was shown that motor imagery plays a particularly important role in action/motor planning. Given the research into motor imagery and motor planning, it is not much of a stretch to suggest that the subjects to whom the reaching task was described engaged in a simulation of the action. ${ }^{{ }^{\mathrm{I}}}$ This further makes it plausible to think that motor imagery could have been involved in the effect that motor planning had on perception.

The experimental set up in this case suggests a kind of linear relation between action and perception, i.e., the subject engages in the grasping action and thus the perception of the illusion is changed. It should be noted, however, that in realworld circumstances the relation would be dynamic rather than linear. Recall that motor imagery-driven forward models are tied together with sensory feedback in a kind of loop such that action and perception are always tightly tied together.

It is important to clarify what Vishton et al. adds to the points made above.

3I. Of course the results of section I would suggest that the subjects who actually engage in a reaching action use motor imagery simulation as well. My point here is not to suggest otherwise, but just to point out that motor imagery might well explain the fact that the mere description of the action had a similar effect to the actual action. 
In 3.I it was shown that motor imagery can combine with visual perception in instances where the two are consciously discernible (as in the rock climber and sculptor examples) and that visual imagery can combine with visual perception in instances where the two are not consciously discernible (as in the shape matching and memory color effect cases). But in the Vishton et al. experiment, motor planning is said to affect "the nature of visual size perception" (2007: 7I8). The implication is that it is the visual perception itself that is affected such that one would say that (as in the shape matching and memory color effect examples) there is a single unified experience. One does not consciously discern the motor planning from the visual experience of the central disk in the Ebbinghaus illusion case in the same manner as one discerns the grip-planning from the visual experience of the rock in the rock-climbing case. This is because the motor planning directly affects low-level visual processing (Vishton et al. 2007: 7 I 7). Thus, while Vishton et al. do not directly present a case of motor imagery combining with visual perception in a unified experience, the relation between motor planning and motor imagery places their study in the vicinity of such a result. Taken as a whole, the results of 3.1 and 3.2 make plausible the idea that motor imagery can affect our visual perceptual experience in such a way that a unified experience results. And this is exactly what is needed to support the Merleau-Pontyian phenomenological descriptions of opportunities for action being directly perceived.

\section{Motor Imagery in the Merleau-Pontyian Case}

In order to both summarize the foregoing material and clarify the claim that motor imagery can help vindicate the Merleau-Pontyian phenomenological descriptions, the results of sections I-III can be fitted into a description of one of the MerleauPontyian cases. The following will use the organist case, though the same kind of description could be given for the soccer player case (or Romdenh-Romluc's (2007:46) martial artist case, or other cases of skilled action).

The experienced organist has developed the habit of organ playing, which means that, in Merleau-Ponty's terms, her body has sedimented an "ensemble of paths already traced" (I983: 210) and thus created in the body "preestablished circuits" (2OI2: 89) that can be engaged in new acts of organ playing. This MerleauPontyian language fits with Jeannerod's language of motor representations being stored as dynamic procedures wired into the motor system. When the organist sits down at the new organ, she prepares for the action of playing by implicitly engaging motor imagery that draws on these preestablished circuits to simulate the action of playing. This simulation both leads to the action of playing, and plays a role in the deployment of a forward model that can regulate the organist's activity.

The organist's non-conscious motor imagery is a part of a motor intention

$$
\text { Ergo } \cdot \text { vol. I, no. } 7 \cdot 2014
$$


that is not a static pre-action plan; rather it unfolds dynamically in a manner that is "immanent in the movement" (2OI2: II3). This is because the forward model's predictive emulation, in which the motor imagery plays a role, is "geared into the world"; it both anticipates sensory feedback via filtering and responds to that feedback through continuous updating. ${ }^{32}$ Thus by engaging in motor imagery simulation and forward model emulation, the organist "projects" her ability to play upon the new organ in a manner that reflects "the double moment of sedimentation and spontaneity" (2OI2: I32). This projection of the organist's possibilities qualitatively affects her perceptual experience such that the keyboard is presented as a place through which musical "value appears in the world" (20I2: I47), i.e., it presents the opportunity to play music. Specifying the exact mechanism through which the imagery affects the perceptual experience is beyond the scope of this paper, but section III suggests at least three possibilities.

First, it may be the case that some of the qualitative aspects of the kinesthetic contents of the motor image combine with the qualitative aspects of the occurrent perceptual experience in a manner akin to Macpherson's hypothesis regarding the memory color effect. Note that Macpherson's proposal can accommodate the implicit status of the motor image; she writes that "the sort of imaginative process that will typically take place in my two-step mechanism is the non-deliberate, unbidden kind . . . typically, one will not even realise that one is undergoing an imaginative process or that one's imagination is influencing one's experience" (201 2: 55 ). Thus as the imaginative kinesthetic content of moving to play the organ combines with the visual experience of the organ, the organist (to paraphrase Macpherson) has an experience as of an organ-to-be-played. Presumably this "combining" would involve the imagery affecting (via interference or facilitation) the perception such that they cannot be consciously distinguished.

Second, it may be the case that the kinesthetic contents of the motor image supplement or "fill in" the visual contents of the organist's perceptual experience. On one hand, this possibility could draw on the examples of cross-modal perception, if we accept that kinesthetic information as it is conveyed in the motor image can supplement the visual scene. On the other hand, one might draw on the example taken from Kosslyn and Sussman wherein imagery supplements vision in recognition tasks. It may be the case that (to paraphrase Kosslyn and Sussman) the organist simply experiences seeing the organ as offering to be played when the content of the motor image matches up with the visual contents. This does strain

32. Merleau-Ponty uses the language of "gearing in" (the French verb is engrener) throughout Phenomenology of Perception. It is, for example, used in the vicinity of the previously quoted passage about motor intentionality (20I2: 26I). In a translator's comment Donald Landes (Merleau-Ponty 20I 2: 496-497 n. 47) helpfully notes that although literal gears predetermine the way in which they will fit together by the shape of their teeth, Merleau-Ponty's use implies not that the body and world fit together in a predetermined way but rather that it is a dynamic process. 
Kosslyn's and Sussman's argument a bit, because in their case the matching is direct due to the fact that visual imagery is being matched with visual experience. A motor image of playing an organ could not match up with a visual experience of an organ in the same way because they come from different perceptual modalities. Nonetheless, it seems plausible that one could retain a looser yet meaningful sense of "match" insofar as the visually perceived object would be seen as the particular type of thing that fits with the imagined action.

Third, one might draw on the experiments of Vishton et al. to find the relevant mechanism. It is possible that when the organist engages in a motor intention via motor imagery, the intention may cause the visual system to "alter the way in which it processes information" (Vishton et al. 2007: 7I3). The kind of effect that is referred to here affects low-level visual processing, so the motor image would affect corresponding elements such as the perception of shape, size (as in Vishton et al.), or distance. Thus if this kind of effect is at play in the organist case, the direct perception of action opportunities would presumably amount to subtle differences in the perceived distance or size of the relevant parts of the organ. So the organist might perceive the stops to be slightly larger, or the keys to be slightly closer, than they would appear to someone not engaged in planning to play. This would in turn make the playable elements of the organ more visually salient, such that they would look more "inviting" for action.

Perhaps one of these possibilities is at play in the organist case. They also do not appear to be mutually exclusive, so perhaps several of them are at play. Or perhaps there is some other explanation; it is not my purpose here to definitively answer the question of what mechanism is at play in the motor imagery-perception interaction. All three of the above options help provide responses to the potential counter-arguments mentioned in the introduction, however. Recall that one might respond to the claim that action opportunities show up directly in perception by arguing that the relevant aspect of the skilled action experience is actually pre-orpost-perceptual. Neither would be the case in any of these instances.

It should be most clear that the effect would not be post-perceptual. Even apart from the consideration of motor imagery this response faces problems. The idea that skilled action depends on post-perceptual judgment seems phenomenologically implausible because of the speed at which much skilled action occurs. It also perhaps unnecessarily intellectualizes action (and both of these points are commonly made in Merleau-Pontyian analyses). The discussion of motor imagery backs up these points, especially insofar as the motor image plays a role in the forward model prediction. If the forward model is necessary because sensory feedback is too slow to completely regulate skilled action, surely post-perceptual judgments-which would have to come after that sensory feedback-would not be up to the task. And in each of the three possible mechanisms discussed above, motor imagery has an effect on the initial perceptual experience of the situation.

$$
\text { Ergo •vol. I, no. } 7 \cdot 2014
$$


But what of the possibility that the effect of motor imagery is pre-perceptual? First, it has to be noted that some of the effects of motor imagery, or of habituated motor abilities generally, would be relevantly pre-perceptual. As Wolpert, Diedrichsen, and Flanagan put the point, "in real-world tasks it has been shown that eye movements can betray the difference between skilled and amateur performers," and they use the example of a skilled cricket batsman who is better able than the amateur to rapidly move his eyes to where the ball is anticipated to be (20II: 739). This is, again, pre-perceptual in the sense that the habituated skill is affecting where the batsman looks rather than affecting the actual visual processing or visual contents. But such pre-perceptual effects do not exclude the possibility of more direct effects on perception, and the two are likely combined in the MerleauPontyian cases. In each of the three possible mechanisms mentioned above, there is such a direct effect. In the Macpherson scenario, the imagery affects the qualitative aspects of the visual experience such that the person who engages in the relevant imagery sees something different from the person who is looking at the same scene but without the imagery. The same would be the case in the perceptual filling-in scenario, because the imagery matches up directly with the visual perception so as to create one experience. Finally, it is clear that the Vishton et al. scenario is not pre-perceptual because the imagery would directly effect low-level perceptual processing.

Recent work on motor imagery thus provides us with the tools to both vindicate and (at least partially) explain the Merleau-Pontyian phenomenological descriptions. Skilled actors can have qualitatively different perceptual experiences of the action scene because of the role that motor imagery plays in preparing for and regulating action.

\section{Acknowledgements}

Thanks go to Robert Briscoe and the students in his Spring 2013 seminar on Philosophy of Perception at Ohio University for a discussion of Merleau-Ponty and cognitive penetration that provided the inspiration for this paper. Briscoe also provided very helpful comments on and discussion of further drafts of the paper. Thanks are also due to two anonymous referees and an editor at Ergo for their helpful comments.

\section{References}

Anema, Helen A. and H. Chris Dijkerman (2013). Motor and Kinesthetic Imagery. In Simon Lacey and Rebecca Lawson (Eds.), Multisensory Imagery (93-I I3). Springer Verlag. 
Bernstein, Nicholas (1967). The Coordination and Regulation of Movements. Pergamon Press.

Briscoe, Robert E. (2008). Vision, Action, and Make-Perceive. Mind and Language, 23(4), 457-497. http://dx.doi.org/10.1111/j.1468-0017.2008.00351.x

Briscoe, Robert E. (20I I). Mental Imagery and The Varieties of Amodal Perception. Pacific Philosophical Quarterly, 92(2), I 53-I73. http://dx.doi.org/10.1111/j.14680114.2011.01393.x

Briscoe, Robert E. (forthcoming). On the Uses of Make-Perceive. In Fiona Macpherson and Fabian Dorsch (Eds.), Perceptual Memory and Perceptual Imagination. Oxford University Press.

Casey, Edward S. (2000). Imagining: A Phenomenological Study (Second ed.). Indiana University Press.

Chemero, Anthony (2009). Radical Embodied Cognitive Science. The MIT Press.

Clark, Andy (1998). Being There. The MIT Press.

Delk, John L. and Samuel Fillenbaum (I965). Differences in Perceived Color as a Function of Characteristic Color. The American Journal of Psychology, 78(2), 290. http://dx.doi. org/10.2307/1420503

Deroy, Ophelia (20I2). Object-Sensitivity versus Cognitive Penetrability of Perception. Philosophical Studies, I62(I), 87-I07. http://dx.doi.org/10.1007/s11098-012-9989-1

de'Sperati, Claudio and Natale Stucchi (I997). Recognizing the Motion of a Graspable Object is Guided by Handedness. NeuroReport, 8(I2), 276I-2765. http://dx.doi. org/10.1097/00001756-199708180-00023

Dreyfus, Hubert L. (2002a). Intelligence without Representation--Merleau-Ponty's Critique of Mental Representation: The Relevance of Phenomenology to Scientific Explanation. Phenomenology and the Cognitive Sciences, I(4), 367-383. http://dx.doi. org/10.1023/A:1021351606209

Dreyfus, Hubert L. (2002b). Refocusing the Question: Can There Be Skillful Coping without Propositional Representations or Brain Representations. Phenomenology and the Cognitive Sciences, I (4), 4 I 3-425. http://dx.doi.org/10.1023/A:1021303723047

Dreyfus, Hubert L. (2007). Reply to Romdenh-Romluc. In Thomas Baldwin (Ed.), Reading Merleau-Ponty (59-69). Routledge.

Dreyfus, Hubert L. and Sean D. Kelly (2007). Heterophenomenology: Heavy-Handed Sleight-of-Hand. Phenomenology and the Cognitive Sciences, 6(I-2), 45-55. http:// dx.doi.org/10.1007/s11097-006-9042-y

Durgin, Frank H., Dinah DeWald, Stephanie Lechich, Zhi Li, and Zachary Ontiveros (20II). Action and Motivation: Measuring Perception or Strategies? Psychonomic Bulletin \& Review, I 8(6), I077-I082. http://dx.doi.org/10.3758/s13423-011-0164-z

Durgin, Frank H., Brennan Klein, Ariana Spiegel, Cassandra J. Strawser, and Morgan Williams (2OI 2). The Social Psychology of Perception Experiments: Hills, Backpacks, Glucose, and the Problem of Generalizability. Journal of Experimental Psychology: Human Perception and Performance 38(6), I $582-\mathrm{I} 595$. http://dx.doi.org/10.1037/a0027805

Ernst, Marc O., Martin S. Banks, and Heinrich H. Bülthoff (2000). Touch Can Change Visual Slant Perception. Nature Neuroscience, 3(I), 69-73. http://dx.doi.org/10.1038/71140

Firestone, Chaz and Brian J. Scholl (2014). "Top-Down” Effects Where None Should Be Found: the El Greco Fallacy in Perception Research. Psychological Science, 25(I), 38 46. http://dx.doi.org/10.1177/0956797613485092

Frak, Victor, Yves Paulignan, and Marc Jeannerod (200I). Orientation of the Opposition 
Axis in Mentally Simulated Grasping. Experimental Brain Research, I36(I), I 20-I 27. http://dx.doi.org/10.1007/s002210000583

Gallagher, Shaun (2005). How the Body Shapes the Mind. Oxford University Press. http:// dx.doi.org/10.1093/0199271941.001.0001

Gallagher, Shaun (2008a). Brainstorming. Imprint Academic.

Gallagher, Shaun (2008b). Are Minimal Representations Still Representations? International Journal of Philosophical Studies, I6(3), 35I-369. http://dx.doi. org/10.1080/09672550802113243

Glotzbach, Philip A. and Harry Heft (I982). Ecological and Phenomenological Contributions to the Psychology of Perception. Nous I6(I), I08-I2I. http://dx.doi. org/10.2307/2215421

Grush, Rick (1997). The Architecture of Representation. Philosophical Psychology, ro(I), 5-23. http://dx.doi.org/10.1080/09515089708573201

Grush, Rick (2004). The Emulation Theory of Representation: Motor Control, Imagery, and Perception. Behavioral and Brain Sciences, 27(3), 377-396. http://dx.doi. org/10.1017/S0140525X04000093

Hobbes, Thomas (I996). Leviathan (Revised Student ed.). Ed. Richard Tuck. Cambridge University Press.

Hopkins, Robert (20I2). What Perky Did Not Show. Analysis 72(3), 43I-439. http:// dx.doi.org/10.1093/analys/ans063

Hume, David (2007). An Enquiry Concerning Human Understanding. Ed. Peter Millican. Oxford University Press.

Hutto, Daniel D. and Erik Myin (2013). Radicalizing Enactivism. MIT Press.

Jeannerod, Marc (I994), The Representing Brain: Neural Correlates of Motor Intention and Imagery. Behavioral and Brain Sciences, I 7(2), I 87-20I. http://dx.doi.org/10.1017/ S0140525X00034026

Jeannerod, Marc (I995). Mental Imagery in the Motor Context. Neuropsychologia, 33(I I), I4I9-I 432. http://dx.doi.org/10.1016/0028-3932(95)00073-C

Jeannerod, Marc (2006). Motor Cognition. Oxford University Press. http://dx.doi. org/10.1093/acprof:oso/9780198569657.001.0001

Jeannerod, Marc and Victor Frak (I999). Mental Imaging of Motor Activity in Humans. Current Opinion in Neurobiology, 9(6), 735-739. http://dx.doi.org/10.1016/S09594388(99)00038-0

Kind, Amy (200I). Putting the Image Back in Imagination. Philosophy and Phenomenological Research, 62(I), 85-I09. http://dx.doi.org/10.1111/j.1933-1592.2001.tb00042.x

Kirsch, Wladimir and Wilfried Kunde, W. (20I3). Visual Near Space Is Scaled to Parameters of Current Action Plans. Journal of Experimental Psychology: Human Perception and Performance, 39(5), I3 I3-I325. http://dx.doi.org/10.1037/a0031074

Kitagawa, Norimichi and Yosuke Igarashi (2005). Tickle Sensation Induced by Hearing a Sound. Japanese Journal of Psychonomic Science, 24(I), I 2 I-I 22.

Kosslyn, Stephen M. and Amy L. Sussman (r994). Roles of Imagery in Perception: Or, There Is No Such Thing as Immaculate Perception. In Michael S. Gazzaniga (Ed.), The Cognitive Neurosciences (I035-I042). MIT Press. http://dx.doi.org/10.1093/acprof:o so/9780195179088.001.0001

Kosslyn, Stephen M., William L. Thompson, and Georgio Ganis (2006). The Case for Mental Imagery. Oxford University Press.

Lewis, Katie J.S., Gregoire Borst, and Stephen M. Kosslyn (2010). Integrating Visual Men- 
tal Images and Visual Percepts: New Evidence for Depictive Representations. Psychological Research, 75(4), 259-27 I. http://dx.doi.org/10.1007/s00426-010-0304-5

Macpherson, Fiona (20I2). Cognitive Penetration of Colour Experience: Rethinking the Issue in Light of an Indirect Mechanism. Philosophy and Phenomenological Research, 84(I), 24-62. http://dx.doi.org/10.1111/j.1933-1592.2010.00481.x

Merleau-Ponty, Maurice (I983). The Structure of Behavior. Trans. Alden L. Fisher. Duquesne University Press.

Merleau-Ponty, Maurice (2010). Structure and Conflicts in Child Consciousness. In Child Psychology and Pedagogy: The Sorbonne Lectures 1949-1952. Trans. Talia Welsh. Northwestern University Press.

Merleau-Ponty, Maurice (20I2). Phenomenology of Perception. Trans. Donald A. Landes. Routledge.

Moran, Aidan, Aymeric Guillot, Tadhg MacIntyre, and Christian Collet (20II). ReImagining Motor Imagery: Building Bridges Between Cognitive Neuroscience and Sport Psychology. British Journal of Psychology, I03(2), 224-247. http://dx.doi. org/10.1111/j.2044-8295.2011.02068.x

Moulton, Samuel T. and Stephen M. Kosslyn (2009). Imagining Predictions: Mental Imagery as Mental Emulation. Philosophical Transactions of the Royal Society B, 364(I 52 I): I 273-I 280. http://dx.doi.org/10.1098/rstb.2008.0314

Reeves, Adam, and Catherine Craver-Lemley (2012). Unmasking the Perky Effect: Spatial Extent of Image Interference on Visual Acuity. Frontiers in Psychology I $5(3)$, I-7.

Romdenh-Romluc, Komarine (2007). Merleau-Ponty and the Power to Reckon With the Possible. In Thomas Baldwin (Ed.), Reading Merleau-Ponty (44-58). Routledge.

Romdenh-Romluc, Komarine (20I I). Agency and Embodied Cognition. Proceedings of the Aristotelian Society, I I I , 79-95. http://dx.doi.org/10.1111/j.1467-9264.2011.00299.x

Ryle, Gilbert (2009). The Concept of Mind (6oth Anniversary ed.). Routledge.

Sanders, John T. (1993). Merleau-Ponty, Gibson, and the Materiality of Meaning. Man and World, 26(3), 287-302. http://dx.doi.org/10.1007/BF01273397

Schilder, Paul (I923). Das Körperschema, Berlin: Springer. http://dx.doi.org/10.1007/9783-662-39795-4

Schubotz, Ricarda I. and D. Yves von Cramon (2004). Brains Have Emulators With Brains: Emulation Economized. Behavioral and Brain Sciences, 27(3), 4I4-4 I 5. http://dx.doi. org/10.1017/S0140525X04400090

Segal, Sydney J. and Vincent Fusella (I970). Influence of Imaged Pictures and Sounds on Detection of Visual and Auditory Signals. Journal of Experimental Psychology, 83 (3), 458-464. http://dx.doi.org/10.1037/h0028840

Segal, Sydney J. (1972). Assimilation of a Stimulus in the Construction of an Image: The Perky Effect Revisited. In Peter W. Sheehan (Ed.) The Function and Nature of Imagery (203-230). Academic Press Incorporated.

Spence, Charles and Ophelia Deroy (2013). Crossmodal Mental Imagery. In Simon Lacey and Rebecca Lawson (Eds.), Multisensory Imagery (I 57-I83). Springer Verlag.

Stanley, Jason (201 I). Know How. Oxford University Press. http://dx.doi.org/10.1093/acp rof:oso/9780199695362.001.0001

Steeves, James B. (200I). The Virtual Body: Merleau-Ponty's Early Philosophy of Imagination. Philosophy Today, 45(4), 370-380. http://dx.doi.org/10.5840/philtoday200145424

Thomas, Nigel J.T. (20I4). Mental Imagery. In Edward N. Zalta (Ed.) The Stanford En- 
cyclopedia of Philosophy. URL = <http://plato.stanford.edu/archives/spr2014/entries/ mental-imagery/>.

Thompson, Evan (2007). Mind in Life: Biology, Phenomenology, and the Sciences of Mind, Belknap Press.

Van Leeuwen, Neil (20I I). Imagination Is Where the Action Is. The Journal of Philosophy, IO8(2), 55-77.

Waller, David, Jeffrey R. Schweitzer, J. Ryan Brunton, and Roger M. Knudson (20I2). A Century of Imagery Research: Reflections on Cheves Perky's Contribution to Our Understanding of Mental Imagery. The American Journal of Psychology I 25(3), 29I-305. http://dx.doi.org/10.5406/amerjpsyc.125.3.0291

Witzel, Christoph, Hanna Valkova, Thorsten Hansen, and Karl L. Gegenfurtner (20I I). Object Knowledge Modulates Colour Appearance. i-Perception, 2(I), I3-49. http:// dx.doi.org/10.1068/i0396

Wolpert, Daniel M., Jörn Diedrichsen, and J. Randall Flanagan (20I I). Principles of Sensorimotor Learning. Nature Reviews Neuroscience, I 2, 739-75 I.

Wolpert, Daniel M. and J. Randall Flanagan (2009). Forward Models. In Tim Bayne, Axel Cleeremans, and Patrick Wilken (Eds.) The Oxford Companion to Consciousness (295-296). Oxford University Press. 